\title{
INTERthesis,
}

\section{OS DESAFIOS CONTEMPORÂNEOS DA PRODUÇÃO DO CONHECIMENTO: O APELO PARA INTERDISCIPLINARIDADE ${ }^{1}$}

Claude Raynaut ${ }^{2}$

\section{Resumo:}

Estamos atravessando hoje um momento de reconstrução radical na forma de se pensar tanto o mundo material dentro do qual vivemos e atuamos como a relação que nós, Seres humanos, estabelecemos - individual ou coletivamente - com esse mesmo mundo. O movimento que está acontecendo agora apela por novos paradigmas, novas categorias de pensamento, novas metodologias de pesquisa, novas formas de ensino. Muitos dos problemas que a ciência e as técnicas contemporâneas devem enfrentar não se deixam reduzir ao recorte disciplinar em função do qual se estruturaram historicamente as instituições de ensino e de pesquisa. Colaborações impõem-se entre cientistas com formações marcadas por uma alta especialização. Fronteiras conceituais estabelecidas entre áreas de conhecimento distintas tornam-se permeáveis. Trocas e ajustes metodológicos são necessários. O apelo para a colaboração interdisciplinar expressa-se hoje com cada vez mais força. Pontes são lançadas entre abordagens setoriais da realidade. Interdisciplinas nascem e acham espaço institucional. As inovações tecnológicas mobilizam competências oriundas de horizontes científicos longínquos. Apesar dessa pujante dinâmica histórica, inúmeros obstáculos permanecem. Alguns deles são expressão de resistências institucionais e de confrontos interpessoais. Outros originam-se na rigidez intelectual imposta por uma formação acadêmica altamente especializada. Até hoje, não se encontra uma definição da interdisciplinaridade que seja consensual, e menos ainda uma doutrina estabelecida que possa ser aplicada ao trabalho de campo. Torna-se, então, imprescindível contribuir a clarificar as bases teóricas e metodológicas sobre as quais pode-se construir um projeto de prática concreta da interdisciplinaridade no domínio do ensino e da pesquisa.

Palavras-chave: Interdisciplinaridade. Epistemologia. Ensino superior. Pesquisa.

A questão da necessidade de ultrapassar as fronteiras disciplinares, para poder conseguir entender problemas do mundo contemporâneo que não se deixam encaixar em domínios e categorias de pensamento estanques, agita a comunidade

\footnotetext{
${ }^{1}$ Esse texto retoma, reorganiza e aprofunda algumas ideais já apresentadas em vários textos anteriores: Raynaut et al., 2002, Raynaut, 2011, Raynaut e Zanoni, 2011. Este texto foi apresentado oralmente no Simpósio Internacional sobre Interdisciplinaridade no Ensino, na Pesquisa e na Extensão - Região Sul, em Outubro 2013, Florianópolis, SC, Brasil.

2 Doutor em Etnologia e Diretor de Pesquisas no Centro de Pesquisas Científicas da França (CNRS) da Universidade de Bordeaux, França. E-mail: craynaut@hotmail.com
}

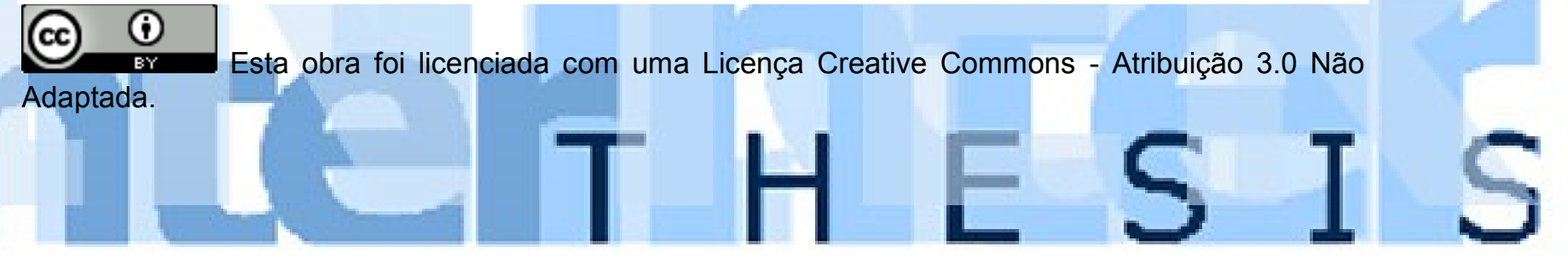


acadêmica e científica em todos os países que desempenham hoje um papel significativo na produção do conhecimento. Os cursos de pós-graduação, que reclamam de uma abordagem inter ou multidisciplinar, multiplicam-se nas universidades, bem como instituições e programas de pesquisa que reúnem especialistas oriundos de vários horizontes científicos. Inúmeros são os artigos e os livros que tratam do assunto. ${ }^{3}$ O Brasil pode ser considerado pioneiro nesse movimento, em particular com a criação, há mais de uma década, de uma ária interdisciplinar a nível da CAPES: iniciativa que visava encorajar as inovações pedagógicas que ultrapassam as fronteiras disciplinares e a reforçar sua legitimidade institucional.

Apesar do caráter extremamente positivo dessa tomada de consciência da necessidade de inovar na produção e transmissão do conhecimento - o pensamento científico implica num constante esforço de crítica intelectual e de renovação teórica e metodológica - o risco existe, no entanto, de ver a crítica das disciplinas e a exigência de interdisciplinaridade tornarem-se um novo conformismo institucional, fator de confusão no modo de se conceber à prática da ciência e as metodologias de ensino. Além do reconhecimento genérico da necessidade de se repensar um recorte disciplinar, às vezes demasiadamente rígido nas instituições de formação e de pesquisa, precisa-se explorar a diversidade de significados, de interpretações divergentes, que veicula consigo uma mesma noção, uma mesma palavra: a de interdisciplinaridade. A confusão não nasce da diversidade, quando ela é devidamente reconhecida e pensada, mas, sim, da incapacidade a identificá-la e aceitá-la.

Há de se reconhecer em primeiro lugar que uma abordagem integrada da resolução dos problemas sempre foi aplicada pelas disciplinas técnicas. Desde os tempos pré-históricos, os gestos técnicos dos primeiros agricultores reclamaram a combinação de uma grande variedade de conhecimentos e de savoir-faire (knowhow): sobre as plantas, os solos, o clima, as ferramentas utilizadas. A invenção da metalúrgica, quanto a ela, exigiu também a integração de observações e conhecimentos muito diversificados para identificar os minerais, explorá-los, fundilos e forjar o metal para Ihe dar a forma desejada. De modo geral, podemos afirmar

\footnotetext{
${ }^{3}$ Pode-se assinalar, entre tantos outros: Klein, 1996, Origgi e Darbellay, 2010, Repko, 2008, Philippi e Silva Neto, 2011.
}

R. Inter. Interdisc. INTERthesis, Florianópolis, v.11, n.1, p. 1-22, Jan./Jun. 2014 
que nenhum processo técnico pode se restringir a um domínio único de competência. A necessidade de juntar conhecimentos e experiências, cada vez mais especializados e mais aprofundados, cresceu com a complexidade dos projetos técnicos.

A construção das grandes catedrais só foi possível graças à colaboração de pedreiros, carpinteiros, ferreiros e vidreiros guiados pelos primeiros engenheiros que desenvolveram os instrumentos conceituais matemáticos para calcular a interação certa das forças, que iam permitir ao edifício permanecer erguido durante séculos.

Já que estamos no Brasil, é preciso valer-se de um exemplo no qual se arraiga a própria existência do país tal como existe hoje. De fato, a descoberta do Brasil por Cabral, em 1500, foi possibilitada pelo projeto lançado, um século antes, por Dom Henrique, o Navegante, para dotar Portugal dos conhecimentos necessários para atingir o subcontinente Índio pelo mar. Ele atraiu sábios, cartógrafos e astrônomos, oriundos de toda a bacia mediterrânea, fundando, assim, o que foi chamado depois a "Escola de Sagres". No decorrer das múltiplas tentativas, feitas ao longo do décimo quinto século para contornar o continente africano, evidenciou-se a falta de maneabilidade dos navios utilizados até então. Especialistas da construção naval e marinheiros foram atraídos dos países árabes, e depois da Holanda, para conceber e realizar um novo tipo de barco: a caravela que conduziu o Vasco de Gama à Índia, o Cristóvão Colombo aos Caraíbas e o Cabral as costas do Brasil. Foi então a conjugação e integração de um amplo leque de saberes e competências - uma "interdisciplinaridade" prática - que possibilitou o sucesso do projeto de Dom Henrique.

É claro que, na época moderna, os desafios a superar passaram por um salto qualitativo e quantitativo sem precedente. A complexidade dos projetos técnicos explodiu com o início da era industrial e os progressos das ciências e das técnicas. Hoje em dia, todo e qualquer projeto industrial, arquitetural ou de criação de infraestruturas (construir uma aeronave, erguer um edifício, lançar uma ponte) mobiliza uma enorme variedade de especialistas. A divisão em disciplinas e departamentos independentes e estanques é uma situação que se encontra, sobretudo, nas instituições acadêmicas. No mundo industrial, seria um obstáculo fatal para a sobrevivência das empresas.

R. Inter. Interdisc. INTERthesis, Florianópolis, v.11, n.1, p. 1-22, Jan./Jun. 2014
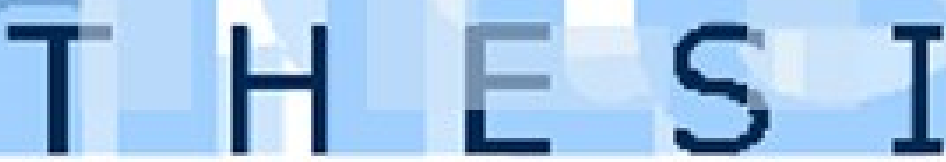
No domínio da pesquisa e da inovação, pode-se dizer que foi nos laboratórios industriais que se iniciou a prática interdisciplinar. O programa de pesquisa da companhia Bell, nos Estados Unidos, durante os anos 30, oferece um exemplo muito ilustrativo do fenômeno. Antecipando o papel crucial dos novos materiais, o departamento da pesquisa e do desenvolvimento contratou especialistas oriundos de especialidades disciplinares muito diversificadas: química, física dos metais, do magnetismo, da eletrônica, da cristalografia e da mecânica quântica. Engenheiros de aplicação, na busca de novas utilizações práticas e de novas patentes que poderiam surgir de suas pesquisas, faziam a coordenação entre todos os especialistas e os reuniam em função de problemas concretos a resolver. Deste trabalho comum nasceu o Transístor (PESTRE, 2010).

No âmbito da academia, a rigidez das fronteiras institucionais entre departamentos disciplinares é muito maior. No entanto, programas de pesquisa envolvendo colaborações interdisciplinares vão também se desenvolvendo.

Em geral, eles possuem um caráter "instrumental” (de prestação de serviço). É o caso quando uma disciplina solicita as competências e o know-how de outras especialidades, às vezes muito distantes dela, mas que têm a capacidade em responder a questões pontuais que ela se coloca ou que podem ajudá-la a ultrapassar obstáculos técnicos frente aos quais ela fica parada. Por exemplo, quando a arqueologia pré-histórica colabora com a geologia, a paleontologia, a paleobotânica e a física nuclear (para as datações), que lhe fornecem informações para que ela possa responder as suas próprias questões, resolver seus próprios problemas.

Inúmeros progressos terapêuticos foram também conseguidos nas universidades médicas e nos hospitais, reunindo uma multiplicidade de conhecimentos e competências práticas. Foi o caso, por exemplo, dos imensos avanços na cirurgia cardíaca. Nasceram progressivamente da colaboração, não apenas entre cirurgiões, clínicos, farmacólogos, imunologistas, mas, também, com físicos e informáticos, trabalhando no domínio das imagens medicais, com engenheiros mecânicos e especialistas dos novos materiais que realizaram próteses cardíacas. Foi a colaboração de todos, no quadro de equipes norteadas por objetivos comuns, que permitiu os progressos dos quais nos beneficiamos hoje.

R. Inter. Interdisc. INTERthesis, Florianópolis, v.11, n.1, p. 1-22, Jan./Jun. 2014 
Essas formas de interdisciplinaridade (na indústria ou na academia), apresentam um caráter pragmático, pontual - organizando-se de modo oportunista para resolverem um problema particular, mas preservando a integridade, a especificidade, de cada disciplina.

No entanto, existem também outras formas de colaboração entre especialidades científicas e técnicas, que não se limitam apenas a um encontro casual, mas, sim, constituem uma convergência que engendra novos campos de estudo estáveis, estruturados, institucionalizados, que podemos chamar de "interdisciplinas". Aqui, não se trata apenas de juntar de modo temporário competências diversificadas para resolver um problema particular, mas, sim, de fundar, com uma perspectiva durável, uma nova estruturação da pesquisa e do ensino. Isto é o que eu chamaria de "interdisciplinaridade de liga" (com analogia com a liga de vários metais que dá nascimento a um novo metal). Os exemplos seriam inumeráveis dessas novas "interdisciplinas" que nasceram durante as décadas passadas.

Um bom exemplo é aquele da biologia molecular que, na esteira da descoberta do ADN e do ARN, e para explorar o funcionamento íntimo da matéria viva, aproxima de modo durável disciplinas inicialmente alheias como a Biologia, a Química, a Física e, para modelizar as informações, a Matemática e a Informática (BENSAUDE-VINCENT, 2004).

Interdisciplinaridade "instrumental" ou "interdisciplinaridade de liga", por mais diferentes entre si que sejam, compartilham uma caraterística comum: as disciplinas chamadas para colaborarem trabalham sobre objetos que podem ser abordados na sua materialidade, sem referência à questão de produção e de circulação do sentido dentro dos sistemas estudados. As interações são biofísicas e químicas. "Mensagens" podem circular, mas, em geral, a palavra é usada de modo metafórico, a "informação" intercambiada não passa de estímulos físicos, químicos, elétricos, que provocam movimentos de reação. Não são, como no caso das culturas humanas, expressões de representações mentais, sentimentos e crenças.

A problemática da interdisciplinaridade coloca-se em termos bem distintos, quando se trata de fazer colaborar as ciências da "materialidade" com aquelas cujo objeto de estudo são as realidades humanas: tanto ao nível dos indivíduos (psicologia) quanto das sociedades (história, sociologia, economia).

R. Inter. Interdisc. INTERthesis, Florianópolis, v.11, n.1, p. 1-22, Jan./Jun. 2014
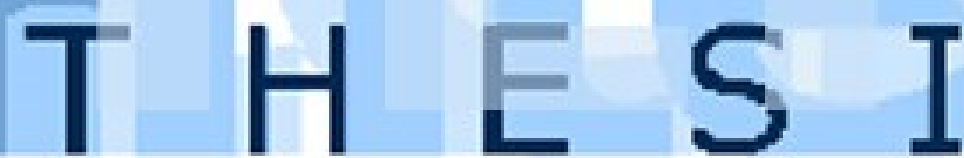
Aqui, os obstáculos a superar são ainda mais desafiadores. Com efeito, a questão da produção e da circulação do sentido se torna central nesse caso. $O$ sentido é a "matéria imaterial" sobre a qual essas disciplinas trabalham. Como integrar a intervenção das ciências humanas e sociais na análise e na resolução de problemas de natureza profundamente híbrida, isto é, que combinam dimensões materiais (relativas à física, à mecânica, à química e à biologia) e dimensões imateriais (relativas à cultura, às relações sociais e políticas, à história, à psicologia, etc.)?

Quando os problemas tratados necessitam a colaboração entre disciplinas que tratam das dimensões, que podemos chamar de materiais, para utilizar uma palavra simplificadora mais expressiva e outras ligadas a suas dimensões humanas e sociais, muitas dificuldades surgem e geram incompreensões entre especialistas que pertencem a universos de pensamento radicalmente diferentes.

Para as ciências da materialidade e para as disciplinas técnicas, o discurso das ciências humanas e sociais não passa de um simples blá-blá-blá. Custa aceitar a ideia de que o domínio da realidade sobre o qual as mesmas trabalham é tão objetivo (possuindo uma existência intrínseca) como o domínio sobre o qual elas mesmas trabalham. No entanto, quando se trata do mundo onde vivemos, em função do qual temos que tomar decisões, nada se pode entender nem fazer sem tomar em conta tal universo de fatos. Vivemos e atuamos na dimensão da história, dimensão dentro da qual o impacto das ideias evidencia-se tão real, tão marcante como aquele das necessidades materiais. Ideias e descobertas intelectuais dão nascimento a outras ideias, outras descobertas que conduzem a reorganizar as sociedades ou a atuar com mais impacto sobre a matéria. Lutas de poder inspiradas por aspirações, busca de identidade e crenças são forças pujantes da história humana. Muito mais sangue humano foi derramado, mais danos ambientais causados - mas, também, muito mais progressos foram conseguidos - em nome de ideologias, de utopias, de princípios morais, religiosos ou políticos, do que na mera busca da satisfação de necessidades físicas. Quando as ciências "duras" e as disciplinas técnicas colaboram com as ciências sociais e humanas na resolução de problemas nos quais se misturam aspectos que pertencem a ambos universos, elas devem se convencer que não são apenas elas que trabalham sobre os fatos reais enquanto os outros pesquisadores estudariam dimensões secundárias que viriam

R. Inter. Interdisc. INTERthesis, Florianópolis, v.11, n.1, p. 1-22, Jan./Jun. 2014
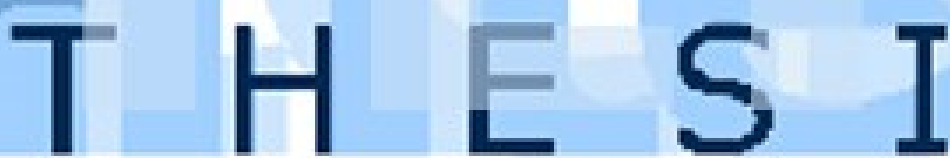
"vestir" ou "perturbar" uma realidade fundamental que teria o privilégio exclusivo da "racionalidade". Elas devem reconhecer que seus parceiros trabalham sobre um nível de realidade tão significativo e rigoroso quanto o seu.

Por outro lado, as ciências humanas, sociais e psicológicas não aceitam facilmente a ideia de que a realidade não material que constitui seu objeto de estudos - relações sociais, ideias, símbolos, sentimentos - é arraigada num alicerce de materialidade. Para pensar, emitir ideias, fazer projetos, o Ser humano depende do funcionamento de seu cérebro, enquanto sistema biofísico. Para permanecer, qualquer sociedade tem que manter as bases materiais de sua reprodução física e demográfica. A própria existência do universo imaterial sobre o qual trabalham as ciências humanas e sociais é condicionada pelas bases materiais que a possibilitam. Mas, aceitar isso não implica no reconhecimento do determinismo da materialidade sobre a imaterialidade. Ainda que possibilitados por processos biofísicos, as ideias, as instituições sociais e os afetos possuem sua própria existência. Interagem entre si, constituem objetos de estudo em si, sem que seja necessário chamar pela biologia ou a física para explicá-los e entendê-los. Ideias geram outras ideias, conceitos possibilitam o surgimento de outros conceitos, formas culturais dão nascimento a novas formas culturais, sentimentos desencadeiam outros sentimentos. Existem encadeamentos de causalidade que não implicam na intervenção de fatos materiais. O único limite sendo a compatibilidade do referencial imaterial de representações mentais e normas que rege a organização e o funcionamento de qualquer sociedade humana e o comportamento de qualquer indivíduo - domínio no qual a criatividade da mente humane pode-se expressar com maior liberdade ${ }^{4}$ - com as exigências últimas de sua reprodução física. Muitos são os exemplos, na história, de civilizações que sumiram por causa do divórcio entre suas crenças religiosas, seus princípios políticos e econômicos e as necessidades impostas pelo ambiente material do qual tiravam os meios de sua sobrevivência física. O universo imaterial ao qual a atividade mental do ser humano dá nascimento, apesar de obedecer a suas próprias lógicas internas, não pode ser totalmente destacado do quadro material que condiciona sua existência. Os cientistas humanos

\footnotetext{
${ }^{4}$ A antropologia social evidencia quão diversas são as soluções culturais e institucionais que as sociedades humanas que povoam o planeta inventaram em respostas aos mesmos problemas fundamentais para sua sobrevivência: reproduzirem-se, alimentarem-se, abrigarem-se das intempéries, defenderem-se contra as agressões.
}

R. Inter. Interdisc. INTERthesis, Florianópolis, v.11, n.1, p. 1-22, Jan./Jun. 2014
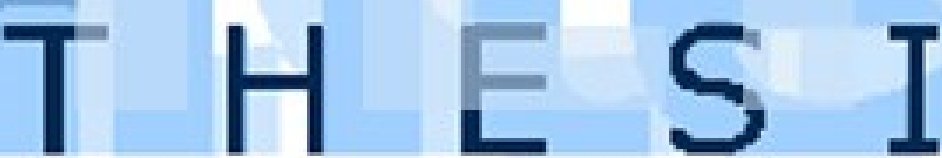
têm que reconhecer essa realidade para poder colaborar sem reticências com as ciências da materialidade.

Apesar das dificuldades de comunicação encontradas, o estatuto da ciência muda. Com a complexificação e a hibridação da realidade contemporânea, torna-se cada vez mais evidente que as dimensões humanas e materiais dos problemas aos quais a ciência se enfrenta estão estreitamente intricadas. Seja qual for o tipo de questão encarada: ambiental, urbanística, relativa às infraestruturas, à produção de bens de consumo, à produção agrícola, à saúde (a lista não teria fim), as temáticas da utilidade social, da aceitabilidade, das consequências esperadas e inesperadas para os indivíduos e as sociedades são primordiais.

Além disso, as ciências e as técnicas são submetidas cada vez mais a dúvidas e preocupações sociais (NOWOTNY; SCOTT; GIBBONS, 2001). Com o custo crescente da pesquisa, o cidadão exerce, diretamente ou pela mediação das instituições políticas, seu peso sobre a escolha dos temas trabalhados. As consequências dos achados científicos e das realizações das tecno-ciências são tais, que hoje não param de alimentar debates sociais e políticos. A multiplicação dos comitês de ética é uma das manifestações evidentes dessa situação.

Mais do que nunca, a Academia deve sair de sua "torre de marfim" e desenvolver seus vínculos com a sociedade. $\mathrm{E}$ as questões oriundas da "demanda social" são profundamente impregnados de blá-blá-blá. Associam estreitamente dimensões materiais e humanas. Neste contexto, a colaboração entre ciências da materialidade, tecno-ciências e ciências humanas é mais do que nunca imprescindível.

\section{NECESSIDADE DE UM QUADRO CONCEITUAL INTEGRADOR}

Para que tal diálogo, tal esforço de compreensão mutual não conduza a uma confusão intelectual, é necessário esclarecer o quadro conceitual dentro do qual se posicionam os dois grandes universos conceituais.

Para isso, podemos propor um modelo heurístico que resume de modo simplificador, mas esclarecedor, os dois "campos", as duas faces distintas da realidade sobre os quais os dois grupos de disciplinas trabalham.

R. Inter. Interdisc. INTERthesis, Florianópolis, v.11, n.1, p. 1-22, Jan./Jun. 2014
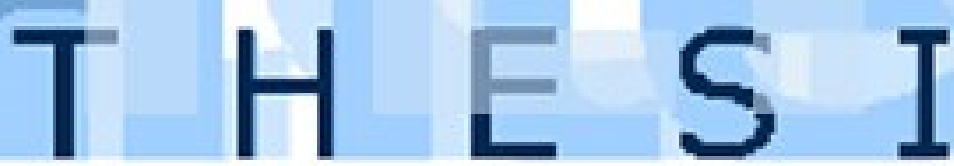


\section{MODELO HEURISTICO}

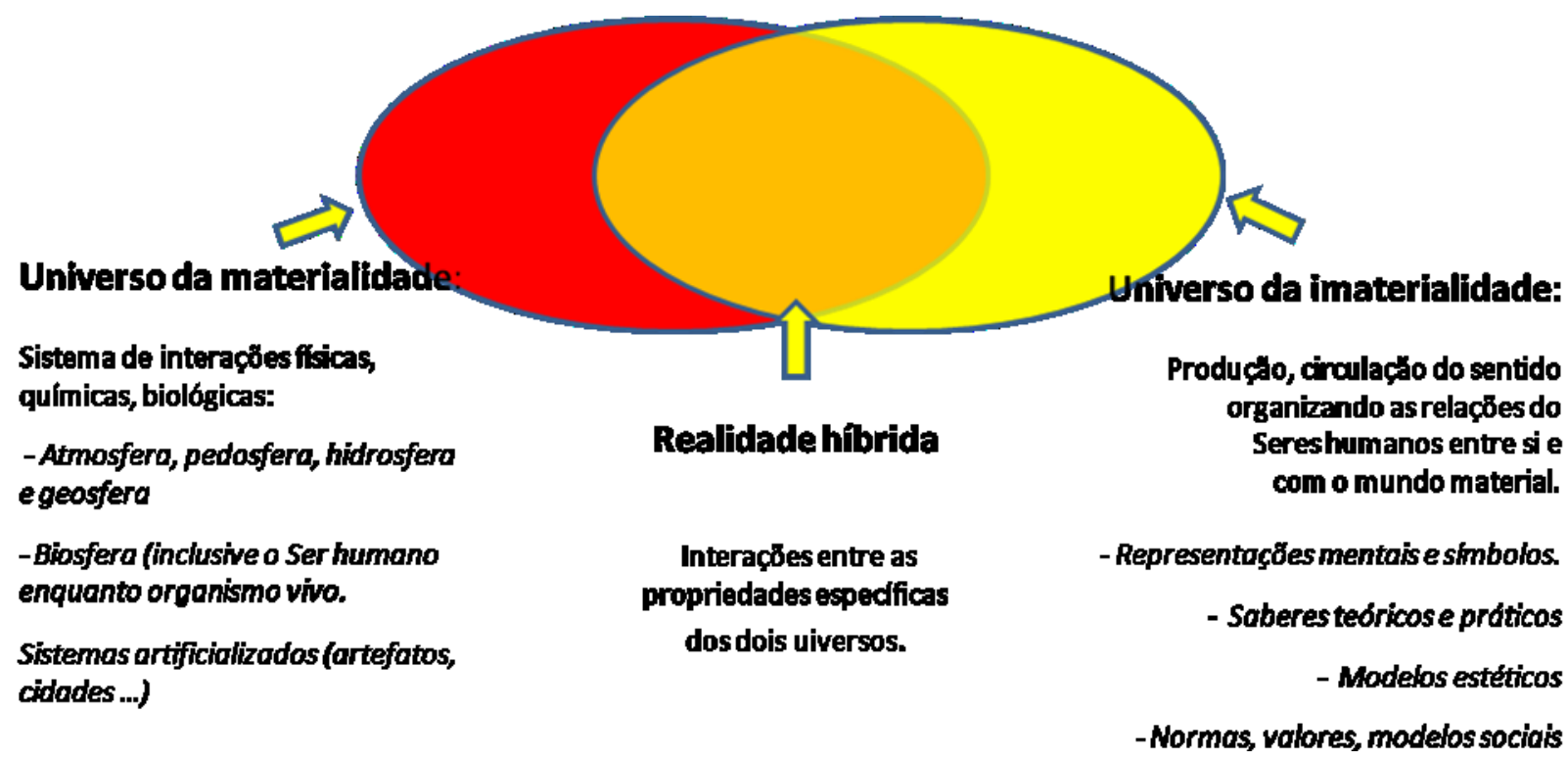

i. O Campo das relações físicas e biológicas, que compreende o conjunto de relações biológicas e físico-químicas tecidas no bojo dos grandes domínios de organização biológica, como a atmosfera, pedosfera, hidrosfera e geosfera. Essa rede de relações forma um sistema, subdividindo-se em muitos subsistemas imbricados e articulados a várias escalas. Ela inclui também uma parte fortemente artificializada da materialidade, a ponto de ser, às vezes, como os objetos técnicos, as cidades, os novos materiais, um produto direto da ação humana (um artefato). São frutos da ação humana - dos pensamentos, dos desejos humanos - mas não deixam de permanecer submetidos a processos da mesma ordem dos meios físicos e biológicos. Este campo da materialidade inclui também o Ser humano - tomado individualmente ou reunido em populações - enquanto considera-se na sua dimensão de organismo vivo, população biológica, agente e objeto de interações biológicas e físico-químicas; e

ii. o Campo das relações não-materiais. Ele compreende o conjunto de processos cuja articulação participa na organização, na reprodução e na transformação das representações mentais do mundo e dos modos de estruturação das relações sociais. Aqui, os fatos que o olhar científico busca identificar, descrever e compreender remetem a processos de produção, de circulação e de transmissão do sentido tanto no ponto de R. Inter. Interdisc. INTERthesis, Florianópolis, v.11, n.1, p. 1-22, Jan./Jun. 2014 
vista da cultura coletiva (representações, valores, normas) quanto dos intercâmbios entre atores sociais. Esses processos desempenham um papel determinante na história de qualquer sociedade e permanecem, em grande parte, autônomos em relação às determinações biológicas e físicoquímicas. As ideias têm a capacidade de engendrar outras ideias. Relações sociais criam condições (tais como tensões, conflitos, solidariedades, construção de identidades, etc.) para a emergência de novas relações sociais. Para construir um conhecimento sobre a organização, o funcionamento e a dinâmica histórica de um sistema social - e isto é o papel das ciências sociais - mas, também, para entender o comportamento dos indivíduos, essa dimensão imaterial da realidade é tão objetiva (no sentido de "possuir uma existência intrínseca") e tão explicativa quanto as condições materiais às quais o mesmo sistema achase submetido.

Distinguir essas duas vertentes da realidade e afirmar que cada uma se constitui como um objeto específico de conhecimento científico é uma etapa essencial em um esforço de descrição e de compreensão da complexidade do mundo. ${ }^{5} \mathrm{E}$ também de respeito mútuo entre as disciplinas. Contudo, não basta reafirmar o caráter intrínseco de cada "campo de fatos". Por distintos que sejam, não deixam de ser estreitamente ligados entre si. O próprio objetivo de um esforço de compreensão da realidade, tal como ela se apresenta na sua hibridação e sua complexidade, reside em descrever e analisar como eles se entrelaçam, se combinam, interagindo entre si.

Cada vez que o ser humano interage com a materialidade, estamos frente a uma realidade híbrida. Já apontamos muitos aspectos dessa hibridação. Uma das caraterísticas da realidade contemporânea é que, por um lado, o mundo material acha-se submetido mais do que nunca, por via das técnicas, aos projetos e desejos humanos e, por outro lado, que a própria humanidade - até na sua capacidade em gerar um universo de ideias e de sentimentos (por natureza imateriais) - revela-se estreitamente ligada a processos biofísicos, solidária do resto do mundo.

\footnotetext{
${ }^{5}$ A complexidade da relação entre essas duas vertentes da realidade foi analisada, na luz das teorias marxistas e estruturalistas, por Godelier (1984) num livro que, apesar de não tratar diretamente do assunto do diálogo interdisciplinar, fornece até hoje marcos teóricos fundamentais para as discussões contemporâneas sobre a interdisciplinaridade.
}

R. Inter. Interdisc. INTERthesis, Florianópolis, v.11, n.1, p. 1-22, Jan./Jun. 2014
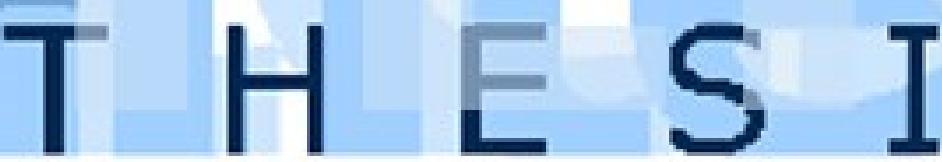
Realidades muito diversas se encaixam dentro desse espaço de interface; a "carga" de materialidade e de imaterialidade de cada situação (sua forma de hibridação) é muito variável. ${ }^{6}$ Para ilustrar a diversidade na combinação entre materialidade e imaterialidade, podemos tomar os seguintes exemplos:

- o astrofísico que trabalha sobre os movimentos dos planetas não precisa introduzir em seus modelos outros fatores que a massa dos mesmos e as forças físicas que se exercem entre eles. Existem sistemas naturais pouco antropizados que podem ser estudados, integrando de modo marginal fenômenos ligados aos projetos e desejos humanos (por exemplo: florestas primárias, alta montanha e, até um certo ponto, oceanos);

- $\quad$ quando se quer analisar uma paisagem (no sentido que os geógrafos dão à palavra), não se pode ignorar que se trata de um sistema natural modelado e transformado, às vezes durante séculos, pelas populações humanas. Não podemos estudá-los como sistemas naturais sem tomar em conta as intervenções humanas. Se queremos entender sua dinâmica passada e tentar prever sua evolução futura, temos que introduzir dentro do modelo elementos ligados à história dos grupos humanos, a suas motivações, a seus objetivos - e então a todas as dimensões ideacionais, afetivas e imaginárias que fazem agir os seres humanos, individual ou coletivamente. A constatação vale igualmente para o corpo humano, pois as suas bases biofísicas são profundamente modeladas e manipuladas pela sociedade e pela cultura. Em ambos exemplos, encontramos uma realidade híbrida, caraterizada por uma inter-relação íntima entre os fatos que as ciências naturais, a biologia e a medicina estudam e as práticas e instituições humanas, expressões de representações sociais, de aspirações, de relações sociais;

-

ao estudar uma cidade, aparelhos ou processos técnicos, novos materiais, alcançamos mais um grau na manipulação da materialidade pelos seres humanos. Todos constituem artefatos que, apesar de

\footnotetext{
${ }^{6}$ Godelier distingue cinco tipos de materialidade que podemos resumir assim: a natureza intocada, a natureza perturbada, a natureza antropizada (que só pode se sustentar na sua forma atual por meio da intervenção do ser humano), os instrumentos utilizados pelo ser humano para explorar, transformar a matéria e os produtos materiais que resultam dessa ação humana (GODELIER, 1984, p. 14-15).
}

R. Inter. Interdisc. INTERthesis, Florianópolis, v.11, n.1, p. 1-22, Jan./Jun. 2014 
obedecerem a exigências e regularidades definidas por sua natureza material, são a expressão direta de projetos e objetivos humanos. Eles têm que cumprir adequadamente os objetivos que lhes foram fixados. Mas, também, eles vão interferir na vida cotidiana dos utilizadores, com consequências não apenas físicas, mas, também, sociais, políticas e culturais, que devem se antecipar. É impossível estudar tais realidades por mais materiais que sejam, sem levar em conta as ideias, os objetivos, as estratégias sociais que dão origem à configuração particular de elementos materiais e de interações biofísicas que constituem; e

- enfim, na outra extremidade do vetor, sistemas sociais, instituições, representações, não podem ser totalmente destacadas do quadro natural e físico no qual as sociedades vivem e se reproduzem. Sem apelar por um determinismo da matéria, deve-se reconhecer que para uma sociedade, uma cultura poderem permanecer, devem respeitar uma compatibilidade entre, por um lado, suas formas de se relacionar com seu entorno material, seu modo de utilizar os recursos existentes e, pelo outro lado, sua visão do mundo, sua maneira de se organizar, seus objetivos e seus projetos. Uma sociedade, um Ser humano, nunca são "desmaterializados". Caso haja descuido durável das exigências da matéria, desaparecerão. No entanto, não se deve perder de vista que a própria dinâmica das ideias (valores morais, conceitos, descobertas cientificas) faz intervir relações de causas e efeitos, que não têm nenhuma dimensão material. Por exemplo, novos conceitos matemáticos criam, por si mesmo, instrumentos de pensamento inéditos que possibilitam a resolução de problemas não resolvidos.

Cada campo disciplinar pode se apoderar de cada uma dessas situações para estudá-la apenas em função de sua própria problemática - sem prestar atenção às outras dimensões também presentes nela. Por exemplo, o Antropólogo pode analisar uma cultura indígena em todas suas manifestações: desde a religião até as práticas de caça e de colheita na floresta, enfatizando a questão das representações sociais e sem prestar atenção aos impactos das atividades sobre os sistemas físiconaturais e sobre a capacidade do grupo em se reproduzir fisicamente. O Biólogo, por sua parte, pode estudar a estrutura e a dinâmica dos ecossistemas naturais sem se

R. Inter. Interdisc. INTERthesis, Florianópolis, v.11, n.1, p. 1-22, Jan./Jun. 2014
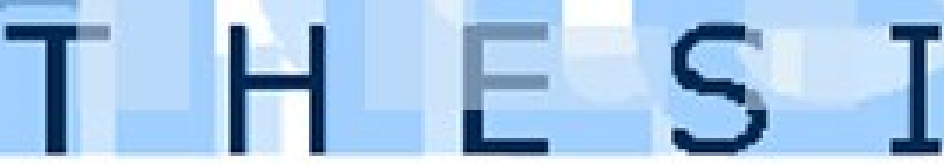
preocupar com as dimensões culturais, sociais, econômicas e com as perturbações que os usos humanos introduzem nos mesmos. Tal pesquisa, unicamente guiada pelos questionamentos de uma disciplina, só é perfeitamente legítima na perspectiva de contribuir para o avanço do conhecimento. Esse tipo de pesquisa, geralmente qualificada de "fundamental", é necessário. Foi assim que muitas descobertas totalmente inesperadas vieram a ser feitas.

Entretanto, existem outras questões, outras problemáticas, que não emergem da própria dinâmica das disciplinas, mas nascem das interrogações formuladas pelas sociedades. Mais do que nunca, como o analisamos acima, as sociedades modernas se defrontam com realidades híbridas, que resultam da interação acelerada entre os avanços das ciências ou das técnicas e a apropriação desses avanços ao serviço dos desejos e sonhos individuais e coletivos. Consequentemente, enfrentam necessidades de conhecimento que não podem ser identificadas e problematizadas apenas por um olhar científico único e que exigem colaborações de especialistas dos dois grandes universos do pensamento científico.

Se a interdisciplinaridade já começa quando colaboram com disciplinas que compartilham um mesmo universo, o desafio se torna muito maior ainda na hora de fazer trabalhar junto ciências que exploram os dois grandes campos inconfundíveis da materialidade e da imaterialidade.

Um desejo de colaborar e um respeito mútuo constituem o pré-requisito imprescindível de uma colaboração bem-sucedida. Mas, por mais necessário que seja esse primeiro passo, não resolve tudo. A prática interdisciplinar não se decreta. Ela não se estabelece espontaneamente pela mera aproximação de disciplinas diferentes. Ela se constrói metodicamente.

Tal processo deve se iniciar a nível de formação dos especialistas, que vão ter que colaborar com a resolução desses problemas complexos e híbridos, aos quais as sociedades contemporâneas são confrontadas. Com efeito, para que cientistas e técnicos oriundos de áreas de conhecimento diferentes possam trabalhar juntos, eles precisam possuir a capacidade de se entenderem mutuamente, de responderem a questões que não surgem da sua própria disciplina; a capacidade de integrarem dentro de seus modelos explicativos informações alheias a seu próprio universo científico.

R. Inter. Interdisc. INTERthesis, Florianópolis, v.11, n.1, p. 1-22, Jan./Jun. 2014
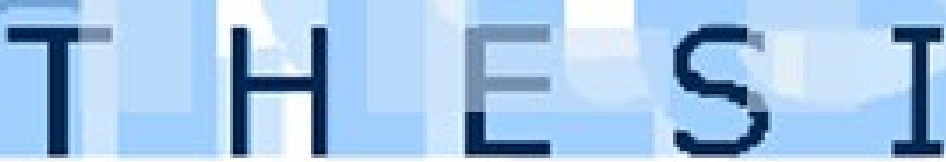
Isto implica em desdobramentos maiores no âmbito dos cursos de formação acadêmica. Após um longo período de hiperespecialização das instituições e programas de formação, um esforço de abertura dos espíritos torna-se, doravante, necessário. Um consenso faz-se hoje sobre esse objetivo, e quase todo mundo concorda sobre a exigência de interdisciplinaridade. A palavra "interdisciplinaridade" veio a ser, doravante, quase um slogan. Mas, como todo e qualquer slogan, ela veicula consigo tamanha ambiguidade. Isto gera uma certa confusão quanto ao conteúdo da noção. Na verdade, existe uma grande diversidade de concepção da interdisciplinaridade em função dos objetivos visados e do público-alvo das formações.

Muitos dos embates e das controversas que surgem quando se fala de "interdisciplinaridade" nascem do fato de que os objetivos e o tipo de interdisciplinaridade dos quais cada um fala não foram definidos claramente. Vamos tentar por em destaque alguns princípios gerais, nos quais se pode pensar para conceber um ciclo de formação que vise proporcionar aos cientistas e técnicos, oriundos de várias áreas disciplinares, os instrumentos intelectuais e metodológicos dos quais precisam para interagirem e colaborarem.

\section{FACETAS DE UMA FORMAÇÃO INTERDISCIPLINAR}

A aprendizagem de uma abordagem intelectual, que permita lançar passarelas entre diversos campos de saber e de competência, exige um trabalho de formação guiado por uma pedagogia adequada. Uma formação à interdisciplinaridade tem que propor então um itinerário pedagógico que permita a cada um, sem perder o que adquiriu durante sua formação inicial ou seu percurso profissional, estabelecer sua capacidade de dialogar com outros especialistas, engajar com eles colaborações concretas.

Aqui, surge um ponto que se precisa esclarecer desde o início. A ideia de interdisciplinaridade desemboca, às vezes, em um sonho intelectual: o de restituir a unicidade do saber; de chegar a novas formas de conhecimento que abranjam e reconciliam as múltiplas faces do saber. O cientista interdisciplinar seria aquele que teria o conhecimento suficiente de um amplo leque de disciplinas diversificadas para poder produzir, por si só, um modelo explicativo sintético de uma realidade

R. Inter. Interdisc. INTERthesis, Florianópolis, v.11, n.1, p. 1-22, Jan./Jun. 2014
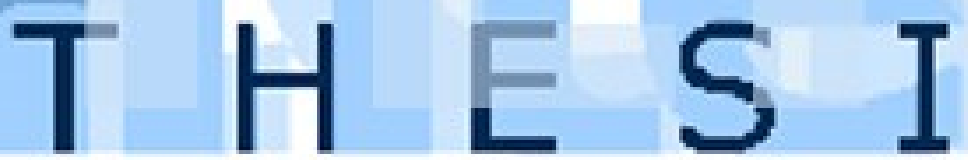
complexa. Um homem (ou mulher) orquestra que saiba tocar de todos os instrumentos da produção do conhecimento. Se a questão filosófica e epistemológica da unicidade da realidade e do carácter artificial e provisório do recorte disciplinar é totalmente pertinente, eu tenho as maiores dúvidas quanto à possibilidade de formar pessoas que possam tratar com igual competência os assuntos mais diversos. Claro que existem alguns espíritos geniais que possuem um saber enciclopédico e uma inteligência amplíssima (no sentido etimológico da palavra: capacidade em "ligar" entre si os fios mais diversos de uma situação). Mas, são exceções, e não podem constituir o padrão alvo de nossos cursos de formação. Além disso, o campo do saber tem se complexificado e aprofundado de tal maneira, que hoje um Leonardo da Vinci não poderia mais existir.

O risco com uma formação que pretenderia formar pessoas interdisciplinares por si só seria produzir criaturas do Frankenstein, formadas de pedaços díspares, mal costuradas e que andam de modo desajeitado.

Um objetivo realista para uma formação interdisciplinar reside em proporcionar a especialistas, dotados de alto nível de formação na sua disciplina, as competências para colaborar, trocar informações, trabalhar coletivamente com cientistas ou técnicos também muito qualificados na sua área de conhecimento e esperteza.

Mas, por modesto que possa parecer tal objetivo, ainda representa um grande desafio pedagógico, na medida em que implica em um trabalho metódico de reconstrução de espíritos moldados, desde a escola até a universidade, por uma formação cada vez mais especializada e rígida.

Os modos de enfrentar e superar tal desafio pedagógico constituem um tema de reflexão em si. Limitamo-nos aqui a evocar alguns objetivos fundamentais a se visarem, sem entrar no detalhe de sua aplicação (deixando para outras palestras, programadas no âmbito do Simpósio, a ocasião de entrar nas dimensões mais concretas desta estratégia de renovação da formação e da pesquisa).

Em breve, tais objetivos fundamentais são:

- $\quad$ Abrir as mentes e baixar as barreiras intelectuais.

O abalamento das certezas disciplinares, a tomada de consciência do caráter parcial da visão da realidade imprimida por qualquer especialização científica ou técnica são condições iniciais necessárias para engajar-se em um movimento de

R. Inter. Interdisc. INTERthesis, Florianópolis, v.11, n.1, p. 1-22, Jan./Jun. 2014
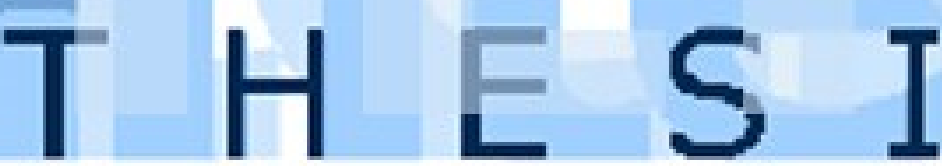
reflexão, que vise ultrapassar as fronteiras entre territórios do saber. Não há possibilidade de interdisciplinaridade se não existirem essas dúvidas iniciais e o desejo íntimo a elas associado. Mas, para progredir no sentido de uma verdadeira abordagem científica, é imprescindível dar mais rigor a tal postura intelectual que não passa, no início, de um sentimento, uma mera intuição. Há de se empreender um trabalho metódico de reconstrução de espíritos moldados da escola até a universidade, por uma formação de caráter especializado, rígido.

A primeira etapa imprescindível no percurso de aprendizagem da interdisciplinaridade consiste então em cumprir as seguintes exigências: desenvolver, em cada aluno, um olhar crítico sobre a atividade de produção do conhecimento em geral e sobre sua própria disciplina em particular; criar as condições iniciais de um diálogo entre especialidades científicas distintas. Uma vez estabelecido esse alicerce da interdisciplinaridade, torna-se possível engajar o processo de construção de uma competência tanto teórica quanto prática.

- $\quad$ Favorecer uma convergência de olhares.

Adquirir uma distância crítica em relação ao que sabemos e ao que sabemos fazer, beneficiar-nos com uma melhor capacidade para comunicarmos com o outro e entendemo-lo: tais são as condições prévias da troca científica. A partir disso, convém progredir na aprendizagem dos instrumentos conceituais e metodológicos que viabilizarão a construção de algo novo: um novo modo de cooperar e cruzar os olhares. Por isso, há de familiarizá-los com uma reflexão coletiva sobre questões complexas e híbridas cujo tratamento mobiliza um amplo leque de competências diversificadas. O objetivo, nessa etapa, será conduzir os alunos à tomada de consciência da necessidade de interagir com outros especialistas, de lançar pontes entre os modos de abordar e tratar os problemas.

- $\quad$ Proporcionar a aprendizagem de práticas e instrumentos concretos.

O encaminhamento intelectual percorrido pelos alunos durante as duas etapas prévias da pedagogia interdisciplinar (baixa das barreiras intelectuais e convergência dos olhares), Ihes terá dado uma forma de distância em relação às certezas, muitas vezes estreitas demais, da sua formação inicial. Terá também aberto as portas que lhes permitirão dialogar além das fronteiras disciplinares. As capacidades novas assim adquiridas, para poderem ser aplicadas com efeito em um processo coletivo de produção do conhecimento ou de resolução de problemas,

R. Inter. Interdisc. INTERthesis, Florianópolis, v.11, n.1, p. 1-22, Jan./Jun. 2014
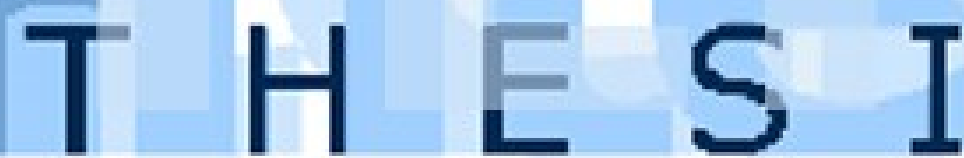
exigem muitas vezes a mobilização de savoir faire e instrumentos práticos dos quais a formação tem também que os dotar. $\mathrm{O}$ objetivo aqui é permitir cruzar, articular e integrar dados heterogêneos. Os métodos e instrumentos a serem chamados variarão assim em função do tipo de interdisciplinaridade alvejado, do perfil dos alunos e dos assuntos tratados. Mas, é fundamental não deixar a simples improvisação, a aproximação e a articulação dos dados, trazidas por disciplinas científicas que trabalham em escalas distintas, de modo qualitativo ou quantitativo, com modos de raciocínio diferenciados.

Para que, no final das contas, os achados dos vários especialistas possam contribuir a uma compreensão coletiva do problema tratado, é necessário valer-se de metodologias adaptadas de tratamento da informação. Muitos instrumentos metodológicos existem hoje e a familiarização com eles deve constar da formação à prática interdisciplinar.

\section{CONCLUSÃO}

Chegamos aqui ao fim de nossa tentativa, muito rápida e resumida, de identificar alguns princípios que devemos ter presente na mente ao falar de interdisciplinaridade.

Após um longo período histórico, durante o qual a especialização dos olhares sobre o mundo em disciplinas distintas tem permitido imensos progressos na elaboração de um saber científico rigoroso sobre o mesmo, a complexidade e o caráter híbrido dos problemas, a se tratar hoje, fazem com que o diálogo e a colaboração entre as disciplinas se torne, doravante, imprescindível. Isto não significa acabar com as disciplinas, mas, sim, criar condições que favoreçam os intercâmbios e a cooperação entre domínios da formação e da pesquisa, que a história das instituições acadêmicas trabalhou para separar em entidades distintas e em universos de pensamento com pouca comunicação entre si.

Se tal colaboração nunca deixou de existir entre disciplinas trabalhando sobre as dimensões materiais da realidade - especialmente no domínio das tecnociências, onde as convergências e hibridações foram frequentes - a comunicação evidencia-se particularmente difícil e precária entre ciências da materialidade e ciências humanas e sociais.

R. Inter. Interdisc. INTERthesis, Florianópolis, v.11, n.1, p. 1-22, Jan./Jun. 2014
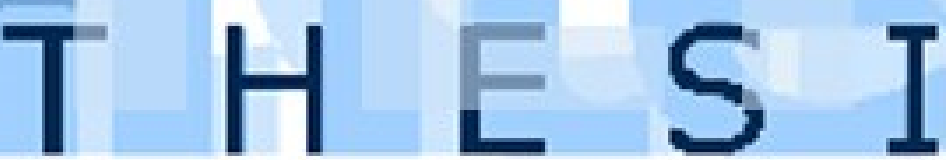
De modo geral, a interdisciplinaridade não é dada de uma vez, pela simples aproximação de científicos, oriundos de vários horizontes. Ela deve se construir de modo metódico porque as formações disciplinares clássicas têm evoluído no sentido de uma especialização crescente. Em geral, os alunos saem dessas formações muito mal preparados para comunicarem, trocarem e compartilharem ideias e questões com pessoas que seguiram um outro percurso intelectual e institucional (mesmo no bojo de cada grande universo conceitual: material e imaterial). Isto significa que um esforço metódico deve ser consentido para criar um espírito novo e competências novas. Tal fase preparatória de reconstrução intelectual é imprescindível para estabelecer o alicerce sobre o qual se fundamentará depois a prática interdisciplinar.

A vontade, o desejo pessoal de ultrapassar as barreiras disciplinares, é o prérequisito incontornável para que tal reconstrução possa se empreender. A interdisciplinaridade não pode ser forçada entre especialistas que não têm dúvidas sobre os limites de sua própria competência. Mas, tal disponibilidade de espirito prévia não basta. Há de se percorrer um caminho pedagógico longo, demorado, minucioso, ao longo do qual a imaginação criativa nunca pode deixar de se associar ao maior rigor intelectual. É o preço que se tem que pagar para evitar, quando se fala de interdisciplinaridade, simplesmente cair na moda, mas, todo ao contrário, engajar-se num esforço, às vezes iconoclasta, de renovação profunda dos modos de produção do conhecimento. Uma renovação que responda ao desafio que nos lança a complexidade e o caráter híbrido das realidades do mundo contemporâneo.

R. Inter. Interdisc. INTERthesis, Florianópolis, v.11, n.1, p. 1-22, Jan./Jun. 2014 


\title{
THE PRESENT CHALLENGES OF THE PRODUCTION OF KNOWLEDGE: THE CALL FOR INTERDISCIPLINARITY
}

\begin{abstract}
We are going through a moment of radical reconstruction in the form of thinking the material world in which we live and act as well as the relationship that we, humans, have established - individually or collectively - with this same world. The movement now calls for new paradigms, new categories of thought, new research methodologies, new ways of teaching. Many of the problems that science and contemporary techniques should face do not let themselves reduce the disciplinary function of clipping from which historically educational institutions and research have een structured. Further collaborations between scientists with backgrounds marked by a high specialization are in demand. Conceptual boundaries established between different areas of knowledge become permeable. Exchanges and methodological adjustments are needed. The call for interdisciplinary collaboration is expressed today with more and more force. Bridges are thrown between sectoral approaches of reality. Interdisciplines are born and find institutional space. Technological innovations mobilize competencies from far-flung scientific horizons. Despite this strong historical dynamics, numerous obstacles remain. Some of them are expression of institutional and interpersonal confront resistances. Others originate in the intellectual rigidity imposed by a highly specialized academic training. To this day, there is not a definition of interdisciplinarity that is consensual and, even less, an established doctrine that can be applied to the field work. Contributing to clarify the theoretical and methodological bases upon which you can build a project of concrete practice of interdisciplinarity in the field of teaching and research becomes essential.

Keywords: Interdisciplinarity. Epistemology. Higher education. Research.
\end{abstract}

\section{LOS DESAFÍOS CONTEMPORÁNEOS DE LA PRODUCCIÓN DEL CONOCIMIENTO: EL APELO PARA LA INTERDISCIPLINARIDAD}

\section{Resumen}

Estamos atravesando hoy un momento de reconstrucción radical en la forma de pensar tanto el mundo material en el cual vivimos y actuamos como la relación que nosotros, seres humanos, establecemos -individual o colectivamente - con ese mismo mundo. El movimiento que está aconteciendo ahora apela a nuevos paradigmas, nuevas categorías de pensamiento, nuevas metodologías de investigación, nuevas formas de enseñanza. Muchos de los problemas que la ciencia y las técnicas contemporáneas deben enfrentar no se dejan reducir al recorte disciplinar en función del cual se estructuraron históricamente las instituciones de enseñanza y de investigación. Se imponen colaboraciones entre científicos con formaciones marcadas por una alta especialización. Se vuelven permeables las fronteras conceptuales establecidas entre áreas de conocimiento distintas. Son necesarios cambios y ajustes metodológicos. El apelo para la colaboración interdisciplinar actualmente se expresa con cada vez más fuerza. Son construidos puentes entre abordajes sectoriales de la realidad. Interdisciplinas nacen y encuentran espacio institucional. Las innovaciones tecnológicas movilizan competencias oriundas de horizontes científicos lejanos. A pesar de esa pujante dinámica histórica, innúmeros obstáculos permanecen. Algunos son expresión de resistencias institucionales y de confrontaciones interpersonales. Otros se originan a

R. Inter. Interdisc. INTERthesis, Florianópolis, v.11, n.1, p. 1-22, Jan./Jun. 2014 
partir de la rigidez intelectual impuesta por una formación académica altamente especializada. Hasta hoy, no se encuentra una definición de la interdisciplinaridad que sea consensual, y todavía menos una doctrina establecida que pueda ser aplicada al trabajo de campo. Por lo tanto, se vuelve imprescindible contribuir para clarificar las bases teóricas y metodológicas sobre las cuales se puede construir un proyecto de práctica concreta de la interdisciplinaridad en el área de la enseñanza y de la investigación.

Palabras-clave: Interdisciplinaridad. Epistemología. Enseñanza superior. Investigación.

R. Inter. Interdisc. INTERthesis, Florianópolis, v.11, n.1, p. 1-22, Jan./Jun. 2014 


\section{REFERÊNCIAS}

BENSAUDE-VINCENT, B. Se libérer de la matière? Fantasmes autour des nouvelles technologies. Paris: INRA, 2004.

CODELIER, M. L'idéel et le matériel. Pensées, économies, sociétés. Paris: Fayard, 1984.

KLEIN, J. T. Crossing Boundaries: Knowledge, disciplinarities, and interdisciplinarities. Charlottesville: University Press of Virginia, 1996.

NOWOTNY, H.; SCOTT, P.; GIBBONS, M. Re-thinking science: knowledge ant the public in an age of uncertainty. Cambridge: Polity, 2001.

ORIGGI, G.; DARBELLAY, F (Dir.). Repenser l'interdisciplinarité. Genève: Slatkine, 2010.

PESTRE, D. L'évolution des champs de savoir, interdisciplinarité et valorisation. In: ORIGGI, G.; DARBELLAY, F. (Dir.). Repenser l'interdisciplinarité. Genève: Slatkine, 2010. p. 39-50.

PHILIPPI, A.; SILVA NETO, A. J. Interdisciplinaridade em Ciência, Tecnologia \& Inovação. Tamboré: Manole, 2011.

RAYNAUT C. et al. Desenvolvimento e Meio Ambiente: a busca pela interdisciplinaridade. Curitiba: Editora UFPR, 2002.

RAYNAUT, C. Interdisciplinaridade: mundo contemporâneo, complexidade e desafios à produção e à aplicação de conhecimentos. In: PHILIPPI, A.; SILVA NETO, A. J. (Eds.). Interdisciplinaridade em Ciência, Tecnologia \& Inovação. Tamboré: Manole, 2011. p. 69-105.

RAYNAUT, C.; ZANONI, M. Reflexões sobre princípios de uma prática interdisciplinar a pesquisa e no ensino superior. In: PHILIPPI, A.; SILVA NETO, A. J. Silva Neto (Eds.). Interdisciplinaridade em Ciência, Tecnologia \& Inovação, Tamboré: Manole, 2011. p. 143-208.

R. Inter. Interdisc. INTERthesis, Florianópolis, v.11, n.1, p. 1-22, Jan./Jun. 2014 
REPKO, A. F. Interdisciplinary Research. Process and Theory. London: Sage, 2008.

Dossiê:

Recebido em: Março de 2014.

Aceito em: Abril de 2014.

R. Inter. Interdisc. INTERthesis, Florianópolis, v.11, n.1, p. 1-22, Jan./Jun. 2014 